\title{
1 Endophytic microbiome variation at the level of a single plant seed
}

\section{Authors}

4 AF Bintarti ${ }^{1}$, A Sulesky-Grieb2 ${ }^{3}$, N Stopnisek ${ }^{1,4}$, A Shade $^{1,2,3,4 *}$

Affiliations

*Corresponding author, shadeash@msu.edu

\section{Abstract}

Like other plant compartments, the seed harbors a microbiome. The members of the

19 seed microbiome are the first to colonize a germinating seedling, and they initiate the

20 trajectory of microbiome assembly for the next plant generation. Therefore, the members of

21 the seed microbiome are important for the dynamics of plant microbiome assembly and the

22 vertical transmission of potentially beneficial symbionts. However, it remains challenging to 
23 assess the microbiome at the individual seed level (and, therefore, for the future individual

24 plant) due to low endophytic microbial biomass, seed exudates that can select for particular

25 members, and high plant and plastid contamination of resulting reads. Here, we report a

26 protocol for extracting metagenomic DNA from an individual seed (common bean, Phaseolus

27 vulgaris L.) with minimal disruption of host tissue, which we expect to be generalizable to other

28 medium- and large- seed plant species. We applied this protocol to quantify the 16S rRNA V4

29 and ITS2 amplicon composition and variability for individual seeds harvested from replicate

30 common bean plants grown under standard, controlled conditions to maintain health. Using

31 metagenomic DNA extractions from individual seeds, we compared seed-to-seed, pod-to-pod,

32 and plant-to-plant microbiomes, and found highest microbiome variability at the plant level.

33 This suggests that several seeds from the same plant could be pooled for microbiome

34 assessment, given experimental designs that apply treatments at the maternal plant level. This

35 study adds protocols and insights to the growing toolkit of approaches to understand the plant-

36 microbiome engagements that support the health of agricultural and environmental

37 ecosystems.

\section{Keywords}

40 16S rRNA, ITS, Phaseolus vulgaris L., legume, pod, fruit, DNA extraction, microbiome assembly 


\section{Introduction}

Seed microbiomes offer a reservoir of microbiota that can be vertically passed from maternal plants to offspring (Mitter et al. 2017; Shade et al. 2017; Truyens et al. 2015) and

47 some of these members have plant-beneficial phenotypes (Adam et al. 2018; Berg and

48 Raaijmakers 2018; Bergna et al. 2018; López-López et al. 2010). Therefore, the seed

49 microbiome is expected to a play a key role in plant health and fitness (Barret et al. 2015), and

50 especially in the assembly and establishment of the developing plant's microbiome (Chesneau

51 et al. 2020). This expected importance of the seed microbiome has fueled recent research

52 activity to use high-throughput sequencing to characterize the seed microbiomes of various

53 plants (e.g., Chartrel et al. 2021; Dai et al. 2020; Eyre et al. 2019; Raj et al. 2019; Rodríguez et al.

54 2020; Xing et al. 2018).

Seed microbiomes include microbial members that live on the seed surface as epiphytes

56 and members that colonize inside the internal tissue of the seed as endophytes (Nelson 2018).

57 Among these microbiome members, endophytes that closely associate with endosperm and

58 embryo are more likely to be transmitted to the next plant generations than are seed-

59 associated epiphytes (Barret et al. 2016; Nelson 2018). By itself, an endophytic association does

60 not confirm that there is a functional benefit or co-evolutionary relationship between the plant

61 and the microbiome member (Nelson 2018). However, endophytic microbes offer the first

62 source of inoculum for the germinating seedling (as reviewed in Nelson 2018; Vujanovic and

63 Germida 2017), and, given the potential for priority effects or pathogen exclusion, these

64 members can have implications for the mature plant's microbial community structure.

65 Therefore, understanding the endophytic seed microbiome is expected to provide insights into 
mechanisms of seed facilitation of microbiome assembly and the vertical transmission of

67 microbiome members over plant generations.

As is true for other plant compartments, different plant species or divergent crop

69 lines/varieties/cultivars often have different seed microbiome composition or structure

70 (Wassermann et al. 2019; Klaedtke et al. 2016; Johnston-Monje and Raizada 2011; López-López

71 et al. 2010). However, many seed microbiome studies have reported generally high variability

72 across seed samples from the same plant type and treatment (Bergna et al. 2018; López-López

73 et al. 2010; Bintarti et al. 2020), with strong explanatory value of either seed origin/seed lot,

74 geographic region or soil edaphic conditions (Chartrel et al. 2021; Klaedtke et al. 2016;

75 Johnston-Monje and Raizada 2011; but see also Adam et al. 2018 for an exception). While these

76 insights may call into question the proportion of "inherited" versus acquired seed microbiome

77 members, the high microbiome variability may be in part due to methods applied to extract the

78 microbial DNA from the seed compartment, and different methods applied across studies. For

79 instance, some studies surface sterilize the seeds while others do not; some germinate the seed

80 prior to microbiome analysis while others do not, etc. One source of microbiome variability

81 could be the common practice of the pooling of many seeds from the same or different plants

82 to produce a composite seed microbiome sample for DNA extraction. Because multiple seeds

83 are investigated at once, it is unclear at what level the most microbiome variability is highest-

84 the seed, the pod or fruit, the plant, or the field or treatment. This information is required to

85 determine the necessary sample size in well-powered experimental designs. More importantly,

86 the question of vertical transmission cannot directly be addressed without seed microbiome

87 assessment of an individual. 
Our study objectives were: 1) to determine the appropriate observational unit of endophytic seed microbiome assessment for common bean (Phaseolus vulgaris L) by quantifying seed-to-seed, pod-to-pod, and plant-to-plant variability in 16S rRNA V4 and ITS2

91 amplicon analyses; and 2) to develop a robust protocol for individual seed microbiome

92 extraction that could be generally applied to other plants that have similarly medium- to large-

93 sized seeds. We found that that plant-to-plant variability under controlled growth conditions

94 exceeded within-plant variability and conclude that seeds can be pooled by maternal plant (but,

95 not across different plants) in study designs that aim to compare seed microbiomes resulting

96 from treatments applied at the plant level.

97

Materials and Methods

Plant growth conditions

Because we targeted the endophytic seed microbiome, surface sterilization of the bean

101 seeds was conducted before germination and planting. To sterilize, seeds were soaked in a

102 solution of $10 \%$ bleach with $0.1 \%$ Tween 20 for 15 minutes, then rinsed four times with sterile

103 water. The final rinse water was plated on tryptic soy agar (TSA) and potato dextrose agar (PDA)

104 plates to test for sterilization efficacy. Sterilized seeds were placed in Petri dishes on sterile

105 tissue paper moistened with sterile water, and allowed to germinate in in the dark for four

106 days. After four days, the radicle had emerged and the germinated seeds were ready to be

107 transferred to the growth chamber. The germinated seeds were planted in three $4.54 \mathrm{~L}$ (1-

108 gallon) pots filled with a 50:50 v/v mixture of agricultural bean field soil and vermiculite. The

109 pots were placed in a BioChambers model SPC-37 growth chamber with a 14-h day/10-h night 
110 cycle at $26^{\circ} \mathrm{C}$ and $22^{\circ} \mathrm{C}$, respectively, $260 \mathrm{mE}$ light intensity, and $50 \%$ relative humidity. All

111 plants received $300 \mathrm{~mL}$ of water every other day and $200 \mathrm{~mL}$ of half-strength Hoagland solution

112 (Hoagland and Arnon 1950) once a week.

\section{Study design}

We planted three germinated seeds per pot and culled to one seedling per pot at the

116 early vegetative growth stage. There were three plant replicates designated as A, B, and C,

117 grown under the above-described conditions for normal, healthy growth. The three plants

118 produced different numbers of pods and total seeds (plant $A=5$ pods, 22 seeds; plant $B=6$

119 pods, 29 seeds; and plant $C=7$ pods, 26 seeds) with the number of seeds varying across pods ( 2

120 to 6 seeds per pod). We aimed to balance and maximize number of seeds across plants.

121 Therefore, we extracted metagenomic DNA from 3 pods from plants A and C, and 6 pods from

122 plant $B$, with 3 to 4 seeds in each pod. For the $16 \mathrm{~S}$ V4 analysis we had 3 pods from plant A (A1,

$123 \mathrm{~A} 2$ and $A 3=4$ seeds), 6 pods from plant $B(B 1$ through $B 6=4$ seeds), and 3 pods from plant $C$

124 ( $C 5=3$ seeds, $C 6$ and $C 7=4$ seeds) for a total of 47 individual seed samples analyzed. For the

125 ITS2 analysis, we were unable to amplify fungal target DNA from pod A1 or pod B1, for a total of

12645 individual seed samples analyzed.

\section{Seed harvest and endophyte metagenomic DNA extraction}


132 individually. To extract the endophytic metagenomic DNA (mgDNA), a protocol was adapted

133 from Barret et al. 2015 and Rezki et al. 2018. First, the seeds were surface-sterilized as above

134 and the seed coat was carefully removed using sterilized forceps. Each seed was then soaked in

$1353 \mathrm{~mL}$ of PBS solution with $0.05 \%$ Tween 20 (hereafter, "soaking solution") overnight at $4^{\circ} \mathrm{C}$ with

136 constant agitation of $170 \mathrm{rpm}$. Since low levels of microbial biomass are expected in single seed

137 extractions, positive and negative controls were included in the extraction protocol. This

138 ensures that if no extractable microbial DNA is present in a sample that it is representative of

139 the sample, rather than the extraction methods. A mock community was used as a DNA

140 extraction positive control by adding one, $75 \mu \mathrm{L}$ aliquot of the ZymoBIOMICS ${ }^{\mathrm{TM}}$ Microbial

141 Community Standard (Zymo Research, Irvine, CA, United States) to $3 \mathrm{~mL}$ of the soaking solution

142 immediately prior to conducting the extraction protocol. Sterile soaking solution (3 $\mathrm{mL})$ was

143 used as a negative DNA extraction control.

144 After soaking overnight, the samples were centrifuged at $4500 \times \mathrm{xg}$ for 60 minutes at $4^{\circ} \mathrm{C}$

145 to pellet any material that had been released from the seed tissues. After centrifugation the

146 seed was removed, and the pelleted material was resuspended in 1-2 $\mathrm{mL}$ of supernatant and

147 transferred to a microcentrifuge tube for DNA extraction using the E.Z.N.A ${ }^{\circledR}$ Bacterial DNA Kit

148 (Omega Bio-tek, Inc. Norcross, GA, United States). The manufacturer's Centrifugation Protocol

149 was used with minor modifications. Specifically, the pelleted seed material was suspended in TE

150 buffer (step 4), the incubation for the lysozyme step was extended to 20 minutes, $30 \mu \mathrm{L}$ of

151 elution buffer was used, and the elution step was extended to a 15 minute incubation. These

152 modifications were performed to maximally recover the limited amount of mgDNA expected 
153 from a single seed. We detail the standard operating protocol, and provide notes on the

154 alternatives that we tested in optimizing this protocol in the Supplementary Material.

155

156 PCR amplification and amplicon sequencing

To confirm successful DNA extraction from the seed pellet, DNA quantification and

158 target gene polymerase chain reaction (PCR) assays were performed. First, the DNA extracted

159 from the seed samples and the positive and negative controls were quantified using the

160 Qubit ${ }^{T M}$ dsDNA BR Assay Kit (ThermoFisher Scientific, Waltham, MA, United States). Then, PCR

161 amplification and sequencing of the V4 region of 16S rRNA bacterial/archaeal gene and the ITS2

162 region of the ITS fungal gene were performed. The V4 region of $16 \mathrm{~S}$ rRNA gene amplification

163 was conducted using 515f (5'-GTGCCAGCMGCCGCGGTAA-3') and 806r (5'-

164 GGACTACHVGGGTWTCTAAT-3') universal primers (Caporaso et al. 2011) under the following

165 conditions: $94^{\circ} \mathrm{C}$ for $3 \mathrm{~min}$, followed by 35 cycles of $94^{\circ} \mathrm{C}(45 \mathrm{~s}), 50^{\circ} \mathrm{C}(60 \mathrm{~s})$, and $72^{\circ} \mathrm{C}(90 \mathrm{~s})$, with

166 a final extension at $72^{\circ} \mathrm{C}(10 \mathrm{~min})$. The amplification was performed in $25 \mu \mathrm{l}$ mixtures containing

$16712.5 \mu \mathrm{l} \mathrm{GoTaq}{ }^{\circledR}$ Green Master Mix (Promega, Madison, WI, United States), $0.625 \mu \mathrm{l}$ of each

168 primer $(20 \mu \mathrm{M}), 2 \mu \mathrm{l}$ of DNA template ( 1 ng per $\mu \mathrm{l})$, and $9.25 \mu$ l nuclease free water. The

169 mgDNA (concentration of $1 \mathrm{ng}$ per $\mu \mathrm{l}$ ) was sequenced at the Research Technology Support

170 Facility (RTSF) Genomics Core, Michigan State sequencing facility using the Illumina MiSeq

171 platform v2 Standard flow cell. The sequencing was performed in a 2x250bp paired end format.

172 The PCR amplification of the ITS2 region of the ITS gene was performed using ITS86f (5'-

173 GTGAATCATCGAATCTTTGAA-3') and ITS4 (5'- TCCTCCGCTTATTGATATGC-3') primers (Op De

174 Beeck et al. 2014) with addition of index adapters by the RTSF Genomics Core. The PCR 
175 amplification of the ITS2 was conducted under the following conditions: $95^{\circ} \mathrm{C}$ for $2 \mathrm{~min}$,

176 followed by 40 cycles of $95^{\circ} \mathrm{C}(30 \mathrm{~s}), 55^{\circ} \mathrm{C}$ for $(30 \mathrm{~s})$, and $72^{\circ} \mathrm{C}$ for $(1 \mathrm{~min})$, with a final extension

177 at $72^{\circ} \mathrm{C}$ for $10 \mathrm{~min}$. The amplification was performed in $50 \mu \mathrm{l}$ mixture containing $20 \mu \mathrm{l}$

178 GoTaq $^{\circledR}$ Green Master Mix (Promega, Madison, WI, United States), $1 \mu$ l of each primer (10 $\left.\mu \mathrm{M}\right)$,

$1791 \mu \mathrm{l}$ of DNA template ( $1 \mathrm{ng}$ per $\mu \mathrm{l})$, and $27 \mu \mathrm{l}$ nuclease free water. The PCR products were

180 purified using QIAquick ${ }^{\circledR}$ PCR Purification Kit (QIAGEN, Hilden, Germany). Purified PCR products

181 with a concentration range 6-10 ng per $\mu$ l were sequenced at the RTSF Genomics Core using

182 Illumina MiSeq platform v2 Standard flow cell and 2x250bp paired end format.

184 Sequence analysis

The USEARCH pipeline (v.10.0.240) was used to merge paired-end bacterial/archaeal

raw reads, filter for low-quality sequences, dereplicate, remove singletons, denoise, and check

187 for chimeras (Edgar and Flyvbjerg 2015). An in-house open reference strategy was performed

188 for OTU clustering (Rideout et al. 2014). First, closed-reference OTU picking was performed by

189 clustering the quality filtered reads against the SILVA database (v.132) (Quast et al. 2013) at

$19097 \%$ identity using USEARCH algorithm (usearch_global command) (Edgar 2010). Then, de novo

191 OTU picking process was performed on the reads that failed to match the reference using

192 UPARSE-OTU algorithm (cluster_otus command) (Edgar 2013) at 97\% identity. Finally, closed-

193 reference and de novo OTUs were combined into a full set of representative sequences. The

194 merged sequences were then mapped back to the representative sequences using the

195 usearch_global command. 
Sequence alignment, taxonomy assignment, non-bacteria/archaea filtering, and

197 phylogenetic diversity calculation were performed using QIIME 1.9.1. The representative

198 sequences were aligned against the SILVA database (v.132) (Caporaso, Kuczynski, et al. 2010)

199 using PyNAST (Caporaso, Bittinger, et al. 2010). The unaligned OTUs and sequences were

200 excluded from the OTU table and the representative sequences file, respectively. Taxonomy

201 assignment was performed using the default classifier method (UCLUST algorithm) at a

202 minimum confidence of 0.9 (Edgar 2010) using SILVA database (v.132) as the reference. Plant

203 contaminants (chloroplast and mitochondria) and unassigned taxa were removed from the OTU

204 table and the representative sequences using filter_taxa_from_otu_table.py and filter_fasta.py

205 command. Filtering the microbial contaminants from the OTU table was conducted in R

206 (v.3.4.2) (R Core Development Team) using the microDecon package (McKnight et al. 2019).

207 Reads were normalized using Cumulative Sum Scaling (CSS) method in metagenomeSeq

208 Bioconductor package on R (Paulson et al. 2013).

processing included merging paired-end reads, removing primers using cutadapt (v.2.1) (Martin

211 2011), dereplication, and singleton removal. OTUs were picked and chimeras removed using de

212 novo clustering at 97\% identity threshold with the UPARSE-OTU algorithm (cluster_otus

213 command, Edgar 2013). Then, all merged sequences were mapped to the clustered reads using

214 usearch_global command to generate an OTU table. Fungal taxonomic classification was

215 performed in CONSTAX (Gdanetz et al. 2017) using RDP Classifier (v.11.5) (Cole et al. 2014;

216 Wang et al. 2007) at a minimum confidence of 0.8 and with the UNITE reference database

217 (release 01-12-2017). Plant and microbial contaminants removal and read normalization were 
218 performed in R (v.3.4.2). Plant contaminants were removed from the OTU table by filtering out

219 OTUs that were assigned into Kingdom Plantae. Microbial contaminants were removed using

220 the microDecon package (McKnight et al. 2019). The CSS method from the metagenomeSeq

221 Bioconductor package was performed to normalize the fungal reads (Paulson et al. 2013).

223 Microbial community analysis

227 diversity were used to analyze the bacterial/archaeal alpha diversity. For fungal alpha diversity,

228 we used richness. The evenness of the seed microbiomes was visualized using rank-abundance

229 curves (Phyloseq package (v.1.28.0) in R (McMurdie and Holmes 2013)). Differences in alpha

230 diversity among plants and pods were determined by fitting the Linear Mixed-Effects Model

231 (LMM) using the Ime() function of the nlme package (version 3.1-152) (Pinheiro et al. 2021). We

232 performed LMM because the study has an unbalanced nested design with pod as the random

233 factor, nested within plant as the fixed factor. Microbial composition and relative abundance

234 were analyzed using the Phyloseq package (v.1.28.0) in R (McMurdie and Holmes 2013).

Beta diversity was calculated using Jaccard distances and visualized using principal

236 coordinate analysis (PCoA) plot. We used the Jaccard index, which is based on presence-

237 absence, rather than a metric based on relativized abundance because we reasoned that the

238 seed microbiome members are likely to be dormant inside the seed prior to germination (Cope-

239 Selby et al. 2017), and that any differences in relative abundances are not directly attributable 
240 to competitive fitness outcomes inside the seed. Furthermore, exponential growth would allow

241 that any viable cell successfully packaged and passaged via the seed could, in theory,

242 successfully colonize the new plant. Nested permutational multivariate analysis of variance

243 (PERMANOVA) using the function nested.npmanova() from the BiodiversityR package (Kindt

244 2020) was performed to assess the microbial community structure among plants and pods. We

245 performed multivariate analysis to check the homogeneity of dispersion (variance) among

246 groups using the function betadisper() (Oksanen et al. 2019). We performed PERMADISP to test

247 the significant differences in dispersions between groups and Tukey's HSD test to determine

248 which groups differ in relation to the dispersions (variances).

249 Power analysis and sample size were calculated using the pwr.t.test() function from the

250 pwr package (v.1.3-0). We performed power analysis of two-category t-test. Because the most

251 microbiome variability was observed across plants, we pooled individual seed sequence profiles

252 in silico at the plant level for this analysis. We calculated Cohen's d effect size given the

253 information of mean and standard deviation of bacterial/archaeal alpha diversity (richness and

254 phylogenetic diversity) from three plant samples from this study: Plant $A$ ( $n=12$; richness: $M=$

$25530.58, S D=6.42$, phylogenetic diversity: $M=4.17, S D=0.89)$, Plant $B(n=24$; richness: $M=$

256 18.21, $S D=7.35$, phylogenetic diversity: $M=2.92, S D=0.82)$ and Plant $C(n=11 ;$ richness: $M=$

257 19.09, $S D=10.95$, phylogenetic diversity: $M=3.09, S D=1.39)$. We calculated the common

258 standard deviation (opool of all groups) using the above information, then we calculated

259 Cohen's d effect size for both richness and phylogenetic diversity. Cohen's d effect size was

260 defined by calculating the difference between the largest and smallest means divided by the

261 square root of the mean square error (or the common standard deviation). Power analysis was 
262 run with Hedges's g effect size (corrected with Cohen's d effect size) and significant level of

2630.05

264

265 Data and code availability

The computational workflows for sequence processing and ecological statistics are

267 available on GitHub (https://github.com/ShadeLab/Bean_seed_variability_Bintarti_2021). Raw

268 sequence data of bacteria/archaea and fungi have been deposited in the Sequence Read

269 Archive (SRA) NCBI database under Bioproject accession number PRJNA714251.

270

271 Results

272 Sequencing summary and microbiome coverage

273 A total of 5,056,769 16S rRNA V4 and 8,756,009 ITS2 quality reads were generated from

27447 mgDNA samples purified from individual seeds for bacteria/archaea, and from 45 samples

275 for fungi. We removed more than $90 \%$ of reads that were plant contaminants (Fig. S1),

276 resulting in 17,128 and 67,878 16S rRNA bacterial/archaeal and ITS fungal reads, respectively.

277 After removing plant and microbial contaminants, we determined 211 bacterial/archaeal and

27857 fungal operational taxonomic units (OTUs) defined at $97 \%$ sequence identity. While the

279 majority of individual seeds from plants A and B had exhaustive to sufficient sequencing effort,

280 some seeds from plant $\mathrm{C}$ did not (Fig. 1a). However, the fungal rarefaction curves reached

281 asymptote and had sufficient effort (Fig. 1b). Both bacterial/archaeal and fungal seed

282 microbiomes were highly uneven with few dominant and many rare taxa, as typical for

283 microbiomes (Fig 1c,d). 


\section{Microbiome Diversity}

There were differences in bacterial/archaeal richness among seeds from different plants

$287($ LMM; $d f=2$, F-value $=6.91, p$-value $=0.015)($ Fig. $2 a)$, where plant $B$ and $C$ had lower seed

288 richness than plant A (Tukey's HSD post hoc test; $p$-value $=0.001$ and 0.006 , respectively).

289 However, bacterial/archaeal richness among seeds from pods collected from the same plant

290 were not different (LMM, p-value > 0.05) (Fig. 2b). Similarly, bacterial/archaeal phylogenetic

291 diversity were different among seeds collected from different plants $(\mathrm{LMMs} ; \mathrm{df}=2, \mathrm{~F}$-value $=$

$2926.56, p$-value $=0.003)($ Fig. $2 c)$, but not among seeds from pods within the same plant (LMM, p-

293 value > 0.05) (Fig. 2d). Plants B and C had lower seed microbiome bacterial/archaeal

294 phylogenetic diversity compared to plant A (Tukey's HSD post hoc test, $p$-value $=0.001$ and

295 0.013, respectively). We observed no differences in fungal richness among seeds from different

296 plants $(\mathrm{LMM} ; \mathrm{df}=2, \mathrm{~F}$-value $=1.11, \mathrm{p}$-value $=0.37)$ (Fig. 2e), and among seeds from pods within

297 the same plant (LMM, p-value > 0.05) (Fig. 2f). To summarize, these results suggest that seed

298 bacterial/archaeal alpha diversity, but not fungal, varied plant to plant.

We detected a difference in seed bacterial/archaeal structure among plants (nested

300 PERMANOVA, df $=2$, F-ratio $=2.94, p$-value $=0.001)($ Fig. $3 a)$, but, again, not among pods from

301 the same plant (nested PERMANOVA, df =9, F-ratio $=0.99, p$-value $=0.63$ ). Though separation

302 among pods and plants are not obvious on the PCoA for the fungal seed microbiomes, we

303 detected modest differences in fungal community structure among seeds from different plants

304 (nested PERMANOVA, df =2, F-rati0 $=1.55, \mathrm{p}$-value $=0.02$ ) (Fig. 3 b), as well as among seeds

305 from pods from the same plant (nested PERMANOVA, df =9, F-rati0 = 1.27, p-value $=0.03$ ). An 
analysis of beta-dispersion revealed that there were differences in seed microbiome dispersion

307 across different plants for bacterial/archaeal communities (PERMADISP, $\mathrm{df}=2$, F-value = 63.9,

$308 p$-value $=0.001)($ Fig.3c), but not for fungal communities (PERMADISP, $d f=2$, F-value $=0.22, p$ -

309 value $=0.798)$ (Fig. 3d). Therefore, statistical differences in the seed microbiome across plants

310 for the bacteria/archaea may be attributed to either centroid or dispersion, while fungal seed

311 communities were different by centroid.

\section{Bean seed microbiome composition}

We identified 135 bacterial/archaeal and 49 fungal taxa at the genus level. The

315 bacterial/archaeal individual seed communities were dominated by taxa from class

316 Gammaproteobacteria (50.47\%), Bacilli (24.48\%), Alphaproteobacteria (8.68 \%), and

317 Bacteroidia (6.59 \%) (Fig. 4a), and include Pseudomonas (13.58 \%), Bacillus (10.2 \%),

318 Acinetobacter (9.5\%), Raoultella (7.09\%), and Escherichia-Shigella (5.19\%) as the major genera.

319 Among members of the class Alphaproteobacteria, we also found genera Bradyrhizobium and

320 Allorhizobium-Neorhizobium-Pararhizobium-Rhizobium with relative abundance of 2.57 and

$3210.85 \%$, respectively. Although seed fungal community composition varied among plants and

322 also pods within plant, the fungal community was dominated by taxa belonging to classes

323 Pezizomycetes (53.44 \%), Agaricomycetes (25.7\%), and Dothideomycetes (11.17 \%) (Fig. 4b),

324 and the genera Helvella (53.44 \%), Gautieria (19.65\%), Acidomyces (7.29\%),

325 Capnodiales_unidentified_sp_23791 (2.52\%), and Phlebiopsis (1.82\%).

A key objective of this research was to understand the sources of variability in the

327 individual bean seed microbiome to inform future study design. Because we found that the 
plant-to-plant seed microbiome variability was highest when grown in control conditions, we performed a power analysis to determine how many plants would be required to observe a treatment effect from seed samples pooled per plant. To detect the effect of treatment to bacterial/archaeal richness and phylogenetic diversity, pooled seeds from 9 and 12 plants are needed, respectively, for $16 \mathrm{~S}$ rRNA richness and phylogenetic diversity, to achieve power of 0.8 ; and 13 and 19 plants to achieve power of 0.95 (Fig. 5).

\section{Discussion}

There remain gaps in our understanding of the persistence and assembly of seed

337 microbiome members, especially across plant generations, and which microbiome members are

338 beneficial and actively selected by, or even co-evolved with, the host. Here, we investigated the

339 variability of the common bean microbiome at the resolution of the individual seed, which is

340 the unit that delivers any vertically transmitted microbiome to the offspring. Because multiple

341 legume seeds within a pod develop as a result of a single flower pollination, one simple

342 hypothesis is that the individual seeds within a pod may harbor a highly similar microbiome if

343 the floral pathway of assembly is prominent. However, recent work has suggested that the

344 endophytic seed microbiome of green bean varieties of common bean likely colonize

345 predominantly via the internal vascular pathway, and not the floral pathway (Chesneau et al.

346 2020), which may result in more homogeneity among seed microbiomes of the same plant.

347 Our data support this finding, as seeds from the same plant (and therefore a common vascular

348 pathway across pods) had relatively low microbiome variability, especially as compared across

349 plants. It is expected that the vascular pathway of seed microbiome assembly is more likely to 
350 colonize the internal seed compartments (e.g., embryo), and therefore more likely to be

351 vertically transmitted (Barret et al. 2016). It is yet unclear whether plant species that have a

352 stronger relative importance of the floral pathway in seed microbiome assembly may exhibit

353 higher microbiome variability at the pod/fruit level. Such an outcome may indicate that the

354 experimental unit should instead be the pod level rather than the plant level for plant species

355 dominated by floral assembly pathways.

356 There are many challenges in analyzing the microbiome of seeds generally and of a

357 single seed in particular, which may be why cultivation-independent studies of single seeds are

358 few (Abdelfattah et al. 2021). Previous studies showed that seeds have low microbial biomass

359 and diversity (Adam et al. 2018; Chesneau et al. 2020; Rezki et al. 2016), especially relative to

360 other plant compartments or soil. Therefore, many studies pool seeds to analyze the

361 aggregated microbiome of many seeds and to get enough microbial biomass for metagenomic

362 DNA extraction (Latz et al. 2021; Bergna et al. 2018; Wassermann et al. 2019; Adam et al. 2018;

363 Johnston-Monje and Raizada 2011; Klaedtke et al. 2016). Generally, microbiome samples that

364 have low biomass have numerous challenges in sequence-based analysis, as discussed

365 elsewhere (Eisenhofer et al. 2019; Bender et al. 2018). First, unknown contaminants, either

366 from nucleic acid kits or from mishandling of the samples, can have relatively high impact on

367 the observed community composition, and so extraction and PCR controls are needed for

368 assessment of contaminants and subtraction of suspected contaminants from the resulting

369 community (Davis et al. 2018). Second, the sparse datasets (e.g., many zero observations for

370 many taxa in many samples) generated from low biomass samples often require special

371 statistical consideration and data normalization (Weiss et al. 2017; Anderson et al. 2011). 
373 expected with analysis of the seed, and this challenge also applies to other plant compartments

374 (Fitzpatrick et al. 2018; Song and Xie 2020). For 16S rRNA amplicon sequencing, the

375 contaminant reads typically derive from host mitochondria and chloroplasts, but ITS or 18S

376 amplicon analysis may also have reads annotated as Plantae. Therefore, nucleic acid extractions

377 may attempt minimal disturbance of the plant tissue that is that target of microbiome

378 investigation; for example, grinding tissues to include in the extraction will result in higher plant

379 DNA contamination than separating microbial biomass from intact tissue. For seeds in

380 particular, it is known that seeds can exude both antimicrobials and attractants to select for

381 particular microbial members early in microbiome assembly of the germinated seed and

382 emerging seedling (Chesneau et al. 2020; Meldau et al. 2012), and there is an active zone of

383 plant and microbiome activity at the seed-soil-interface of a germinating seed (the

384 spermosphere, e.g., Schiltz et al. 2015). Therefore, to target the native endophytic seed

385 microbiome without also allowing for the plant's potential selection for or filtering against

386 particular members, it is important to use dormant seeds and also to minimally disrupt the seed

387 compartment during extraction. Notably, many protocols have opted to first germinate seeds

388 and, therefore, study the outcome of any plant selection prior to analyzing the seed

389 microbiome (Wassermann et al. 2021; Bergna et al. 2018; López-López et al. 2010).

Taking all of these methodological aspects into consideration, this study presents a

391 protocol and analysis pipeline for endophyte microbiome DNA extraction from a single dormant

392 seed that experiences minimal tissue disruption in the extraction process, includes both

393 positive and negative sequencing controls, and includes bioinformatic steps to identify 
394 contamination and remove host signal from the marker gene amplification. Notably, we chose

395 to perform microbiome analysis based on a presence/absence taxon table rather than a table

396 with relativized taxon abundances. This was done in consideration of the ecology of the seed

397 endophyte microbiome members to likely be dormant until germination (Cope-Selby et al.

398 2017), and therefore the differences in relativized abundances do not reflect differences in

399 fitness outcomes inside the dormant seed. We acknowledge that relative abundances could

400 reflect differential microbiome member recruitment by the host plant, but this is not the

401 objective of the study and would be best addressed with a different design to determine the

402 multi-generation consistency and transmission rates of any observed enrichments, which would

403 be supported by assessment of the seed microbiome within individual seeds, and across plant

404 generations.

405 In conclusion, individual seed microbiome assessment provides improved precision in

406 our understanding of plant microbiome assembly and sets the stage for studies of vertical

407 transmission. We found that seeds produced by an individual bean plant can be considered as

408 a unit (for comparative treatment study designs), and that seeds produced by different plants

409 are expected to have slightly different microbiomes, even if grown under the same, controlled

410 conditions and in the same soil source. Future work may consider whether functional

411 redundancy in plant beneficial phenotypes across seed microbiome members may provide one

412 mechanism for consistent outcomes in beneficial plant microbiome establishment.

\section{Acknowledgments}


bioRxiv preprint doi: https://doi.org/10.1101/2021.04.27.441449; this version posted April 27, 2021. The copyright holder for this preprint (which

was not certified by peer review) is the author/funder, who has granted bioRxiv a license to display the preprint in perpetuity. It is made available under aCC-BY-NC-ND 4.0 International license.

416 from the USDA National Institute of Food and Agriculture and Michigan State University

417 AgBioResearch (Hatch). AFB acknowledges a doctoral fellowship from the Fulbright Foundation

418 and from Michigan State University. NS acknowledges support from the Michigan State

419 University Plant Resilience Institute.

420 


\section{References}

422 Abdelfattah, A., Wisniewski, M., Schena, L., and Tack, A. J. M. 2021. Experimental evidence of 423 microbial inheritance in plants and transmission routes from seed to phyllosphere and root. Environ. Microbiol.

425 Adam, E., Bernhart, M., Müller, H., Winkler, J., and Berg, G. 2018. The Cucurbita pepo seed microbiome: genotype-specific composition and implications for breeding. Plant Soil. 422:35-49.

Anderson, M. J., Crist, T. O., Chase, J. M., Vellend, M., Inouye, B. D., Freestone, A. L., et al. 2011. Ecol. Lett. 14:19-28.

Barret, M., Briand, M., Bonneau, S., Préveaux, A., Valière, S., Bouchez, O., et al. 2015. $81: 1257-1266$.

Op De Beeck, M., Lievens, B., Busschaert, P., Declerck, S., Vangronsveld, J., and Colpaert, J. V. metabarcoding studies. PLoS One. 9:e97629. variation and the impact of biomass in targeted 16S rRNA gene sequencing studies. Microbiome. 6:155. 
443 Bergna, A., Cernava, T., Rändler, M., Grosch, R., Zachow, C., and Berg, G. 2018. Tomato seeds preferably transmit plant beneficial endophytes. Phytobiomes J. 2:183-193.

445

446

447

448

449

450

451

452

453

454

455

456

457

458

459

460

461

462

463

464

Bintarti, A. F., Kearns, P. J., Sulesky, A., and Shade, A. 2020. Abiotic treatment to common bean plants results in an altered seed microbiome. bioRxiv. Available at: https://doi.org/10.1101/2020.06.05.134445.

Caporaso, J. G., Bittinger, K., Bushman, F. D., Desantis, T. Z., Andersen, G. L., and Knight, R. 2010. PyNAST: A flexible tool for aligning sequences to a template alignment. Bioinformatics. 26:266-267.

Caporaso, J. G., Kuczynski, J., Stombaugh, J., Bittinger, K., Bushman, F. D., Costello, E. K., et al. 2010. QIIME allows analysis of high-throughput community sequencing data. Nat. Methods. 7:335-336.

Caporaso, J. G., Lauber, C. L., Walters, W. A., Berg-Lyons, D., Lozupone, C. A., Turnbaugh, P. J., et al. 2011. Global patterns of $16 \mathrm{~S}$ rRNA diversity at a depth of millions of sequences per sample. Proc. Natl. Acad. Sci. U. S. A. 108:4516-4522.

Chartrel, V., Dugat-Bony, E., Sarthou, A. S., Huchette, S., Bonnarme, P., and Irlinger, F. 2021. The microbial community associated with pea seeds (Pisum sativum) of different geographical origins. Plant Soil.

Chesneau, G., Torres-Cortes, G., Briand, M., Darrasse, A., Preveaux, A., Marais, C., et al. 2020. Temporal dynamics of bacterial communities during seed development and maturation. FEMS Microbiol. Ecol. 96.

Cole, J. R., Wang, Q., Fish, J. A., Chai, B., McGarrell, D. M., Sun, Y., et al. 2014. Ribosomal Database Project: Data and tools for high throughput rRNA analysis. Nucleic Acids Res. 
42.

Cope-Selby, N., Cookson, A., Squance, M., Donnison, I., Flavell, R., and Farrar, K. 2017. inheritance of endophytes, plant evolution and breeding. GCB Bioenergy. 9:57-77. the seed-resident microbiome of four Leguminous and three Gramineous forages. Microb. Biotechnol. 13:1461-1476.

472 Davis, N. M., Proctor, Di. M., Holmes, S. P., Relman, D. A., and Callahan, B. J. 2018. Simple statistical identification and removal of contaminant sequences in marker-gene and metagenomics data. Microbiome. 6.

Edgar, R. C. 2010. Search and clustering orders of magnitude faster than BLAST. Bioinformatics.

477 Edgar, R. C. 2013. UPARSE: Highly accurate OTU sequences from microbial amplicon reads. Nat. Methods. 10:996-998.

Edgar, R. C., and Flyvbjerg, H. 2015. Error filtering, pair assembly and error correction for nextgeneration sequencing reads. Bioinformatics. 31:3476-3482.

Eisenhofer, R., Minich, J. J., Marotz, C., Cooper, A., Knight, R., and Weyrich, L. S. 2019. Recommendations. Trends Microbiol. 27:105-117. core rice seed microbiome. Phytobiomes J. 3:148-157.

486 Fitzpatrick, C. R., Lu-Irving, P., Copeland, J., Guttman, D. S., Wang, P. W., Baltrus, D. A., et al. 
2018. Chloroplast sequence variation and the efficacy of peptide nucleic acids for blocking host amplification in plant microbiome studies. Microbiome. 6.

Gdanetz, K., Benucci, G. M. N., Vande Pol, N., and Bonito, G. 2017. CONSTAX: A tool for improved taxonomic resolution of environmental fungal ITS sequences. BMC Bioinformatics. 18.

Hoagland, D. R., and Arnon, D. I. 1950. The water-culture method for growing plants without soil. Circ. Calif. Agric. Exp. Stn. 347:32.

Johnston-Monje, D., and Raizada, M. N. 2011. Conservation and Diversity of Seed Associated Endophytes in Zea across Boundaries of Evolution, Ethnography and Ecology. PLoS One. 6:e20396.

Kindt, R. 2020. BiodiversityR: Package for Community Ecology and Suitability Analysis. R package version 2.13-1. https://cran.rproject.org/web/packages/BiodiversityR/index.html.

Klaedtke, S., Jacques, M. A., Raggi, L., Préveaux, A., Bonneau, S., Negri, V., et al. 2016. Terroir is a key driver of seed-associated microbial assemblages. Environ. Microbiol. 18:1792-

Latz, M. A. C., Kerrn, M. H., Sørensen, H., Collinge, D. B., Jensen, B., Brown, J. K. M., et al. 2021. Succession of the fungal endophytic microbiome of wheat is dependent on tissuespecific interactions between host genotype and environment. Sci. Total Environ. 759:143804. 
species such as Rhizobium endophyticum sp. nov. Syst. Appl. Microbiol. 33:322-327.

510

511

512

513

514

515

Martin, M. 2011. Cutadapt Removes Adapter Sequences from High-Throughput Sequencing Reads. EMBnet.journal. 17:10-12.

McKnight, D. T., Huerlimann, R., Bower, D. S., Schwarzkopf, L., Alford, R. A., and Zenger, K. R. 2019. microDecon: A highly accurate read-subtraction tool for the post-sequencing removal of contamination in metabarcoding studies. Environ. DNA. 1:14-25.

McMurdie, P. J., and Holmes, S. 2013. Phyloseq: An R Package for Reproducible Interactive Analysis and Graphics of Microbiome Census Data. PLoS One. 8.

Meldau, D. G., Long, H. H., and Baldwin, L. T. 2012. A native plant growth promoting bacterium, Bacillus sp. B55, rescues growth performance of an ethylene-insensitive plant genotype in nature. Front. Plant Sci. 3.

Mitter, B., Pfaffenbichler, N., Flavell, R., Compant, S., Antonielli, L., Petric, A., et al. 2017. A new approach to modify plant microbiomes and traits by introducing beneficial bacteria at flowering into progeny seeds. Front. Microbiol. 8:1-10.

Nelson, E. B. 2018. The seed microbiome: Origins, interactions, and impacts. Plant Soil. 422:734.

Oksanen, J., Blanchet, F. G., Friendly, M., Kindt, R., Legendre, P., McGlinn, D., et al. 2019. vegan: Community Ecology Package. R package version 2.5-7. https://CRAN.Rproject.org/package=vegan .

Paulson, J. N., Colin Stine, O., Bravo, H. C., and Pop, M. 2013. Differential abundance analysis for microbial marker-gene surveys. Nat. Methods. 10:1200-1202.

Pinheiro, J., Bates, D., DebRoy, S., and Sarkar, D. 2021. nlme: Linear and Nonlinear Mixed Effects 
Models. R package version 3.1-152. https://CRAN.R-project.org/package=nlme.

532 Quast, C., Pruesse, E., Yilmaz, P., Gerken, J., Schweer, T., Yarza, P., et al. 2013. The SILVA ribosomal RNA gene database project: Improved data processing and web-based tools. Nucleic Acids Res. 41:D590-D596.

Raj, G., Shadab, M., Deka, S., Das, M., Baruah, J., Bharali, R., et al. 2019. Seed interior microbiome of rice genotypes indigenous to three agroecosystems of Indo-Burma biodiversity hotspot. BMC Genomics. 20:924.

Rezki, S., Campion, C., Iacomi-Vasilescu, B., Preveaux, A., Toualbia, Y., Bonneau, S., et al. 2016. Differences in stability of seed-associated microbial assemblages in response to invasion by phytopathogenic microorganisms. PeerJ. 4:e1923.

Rezki, S., Campion, C., Simoneau, P., Jacques, M.-A., Shade, A., and Barret, M. 2018. Assembly of seed-associated microbial communities within and across successive plant generations. Plant Soil. 422:67-79.

Rideout, J. R., He, Y., Navas-Molina, J. A., Walters, W. A., Ursell, L. K., Gibbons, S. M., et al. 2014. definitions and scales to billions of sequences. PeerJ. 2:e545.

547 Rodríguez, C. E., Antonielli, L., Mitter, B., Trognitz, F., and Sessitsch, A. 2020. Heritability and functional importance of the setaria viridis bacterial seed microbiome. Phytobiomes J.

550 Schiltz, S., Gaillard, I., Pawlicki-Jullian, N., Thiombiano, B., Mesnard, F., and Gontier, E. 2015. A review: What is the spermosphere and how can it be studied? J. Appl. Microbiol. 119:1467-1481. 
553 Shade, A., Jacques, M.-A. M. A. M.-A., and Barret, M. 2017. Ecological patterns of seed microbiome diversity, transmission, and assembly.

555 Song, L., and Xie, K. 2020. Engineering CRISPR/Cas9 to mitigate abundant host contamination for $16 \mathrm{~S}$ rRNA gene-based amplicon sequencing. Microbiome. 8.

Truyens, S., Weyens, N., Cuypers, A., and Vangronsveld, J. 2015. Bacterial seed endophytes: Genera, vertical transmission and interaction with plants. Environ. Microbiol. Rep. 7:4050.

Vujanovic, V., and Germida, J. J. 2017. Seed endosymbiosis: A vital relationship in providing prenatal care to plants. Can. J. Plant Sci. 97:971-981.

Wang, Q., Garrity, G. M., Tiedje, J. M., and Cole, J. R. 2007. Naïve Bayesian classifier for rapid assignment of rRNA sequences into the new bacterial taxonomy. Appl. Environ. Microbiol. 73:5261-5267.

Wassermann, B., Cernava, T., Müller, H., Berg, C., and Berg, G. 2019. Seeds of native alpine plants host unique microbial communities embedded in cross-kingdom networks.

Wassermann, B., Rybakova, D., Adam, E., Zachow, C., Bernhard, M., Müller, M., et al. 2021. Microbiome. 7:108.

571 Weiss, S., Xu, Z. Z., Peddada, S., Amir, A., Bittinger, K., Gonzalez, A., et al. 2017. Normalization and microbial differential abundance strategies depend upon data characteristics. Microbiome. 5.

574 Xing, H. Q., Ma, J. C., Xu, B. L., Zhang, S. W., Wang, J., Cao, L., et al. 2018. Mycobiota of maize 
bioRxiv preprint doi: https://doi.org/10.1101/2021.04.27.441449; this version posted April 27, 2021. The copyright holder for this preprint (which

was not certified by peer review) is the author/funder, who has granted bioRxiv a license to display the preprint in perpetuity. It is made available under aCC-BY-NC-ND 4.0 International license.

seeds revealed by rDNA-ITS sequence analysis of samples with varying storage times.

576 Microbiologyopen. 7.

577

578 


\section{Figure Legends}

Figure 1. Rarefaction curves of bacteria/archaea (a) and fungi (b) from seed samples (marked) at $97 \%$ of clustering threshold were constructed by plotting the OTU number after decontamination (microbial contaminants removal) to the sequence (read) number. The rarefaction curves were constructed using vegan package (v2.5-4). Rank abundance curve of decontaminated and normalized bacterial/archaeal (c) and fungal (d) OTU tables. Samples ( $n=47$ and $n=45$ for bacteria/archaea and fungi, respectively) were grouped by plant.

Figure 2. Bacterial/archaeal richness among plants were different (linear mixed-effects model,

$588 \mathrm{LMM} ; \mathrm{df}=2, \mathrm{~F}$-value $=6.91, \mathrm{p}$-value $=0.015)(\mathrm{a})$, but not among pods within plant $(\mathrm{p}$-value $>$

591 Bacterial/archaeal phylogenetic diversity among plants were different (linear mixed-effects

592 model, $\mathrm{LMM} ; \mathrm{df}=2, \mathrm{~F}$-value $=6.56, \mathrm{p}$-value $=0.003)(\mathrm{c})$, but not among pods within plant $(p$ -

593 value $>0.05$ ) (d). Specifically, plant B and C displayed lower bacterial/archaeal phylogenetic

594 diversity compared to the plant A (Tukey's HSD post hoc test, p-value $=0.001$ and 0.013 ,

595 respectively). Fungal richness was not different among plants (linear mixed-effects model,

$596 \mathrm{LMM} ; \mathrm{df}=2, \mathrm{~F}$-value $=1.11, \mathrm{p}$-value $=0.37)(\mathrm{e})$ and among pods within plant $(\mathrm{p}$-value $=0.55)(\mathrm{f})$.

598 Figure 3. Principal coordinate analysis (PCoA) plot based on Jaccard dissimilarities of

599 bacterial/archaeal (a) and fungal (b) OTUs. The samples were plotted and grouped based on 
601 that seed bacterial/archaeal community structure differ among plants (nested PERMANOVA, df

$602=2$, F-ratio $=2.94, p$-value $=0.002$ ) but not pods (nested PERMANOVA, df =9, F-ratio $=0.99, p$ -

603 value $=0.63)$. Statistical analysis also showed that seed fungal community structure differs

604 among plants (nested PERMANOVA, df =2, F-rati0 $=1.55, \mathrm{p}$-value $=0.023$ ) and pods (nested

605 PERMANOVA, $d f=9$, F-ratio $=1.27, p$-value $=0.03)$. Distance to centroid analysis using

606 betadisper function from the vegan package revealed that there is variation in

607 bacterial/archaeal Beta diversity among plant (PERMADISP, $d f=2, F$-value $=63.9, p$-value $=$

$6089.6 e-14)(c)$. In contrast, there were no variation in fungal Beta diversity among plant

609 (PERMADISP, $d f=2$, F-value $=0.22, p$-value $=0.802)(d)$.

610

611 Figure 4. Bar plot represents mean relative abundances of bacterial/archaeal (a) and fungal (b)

612 classes detected across plants. For bacteria/archaea, each pod consisted of 4 seeds (except for

613 C5; 3 seeds); and for fungi, each pod consisted of 4 seeds (except for A1, B1 and C5; 3 seeds).

614 The endophyte microbiome was assessed from the DNA extracted from single seed collected

615 from each pod. Bacterial/archaeal and fungal classes with mean relative abundances of less

616 than $10 \%$ were grouped into the 'Other' classification, which includes many lineages (not

617 monophyletic).

619 Figure 5. Analysis of power using pwr.t.test() function from the pwr package revealed that an

620 effect of treatment on the 16S rRNA bacterial/archaeal alpha diversity (richness (a) and

621 phylogenetic diversity (b)) would be detectable 12 plants at a power of 0.8 . Because the

622 highest seed microbiome variability was at the maternal plant level, individual seed microbiome 
bioRxiv preprint doi: https://doi.org/10.1101/2021.04.27.441449; this version posted April 27, 2021. The copyright holder for this preprint (which

was not certified by peer review) is the author/funder, who has granted bioRxiv a license to display the preprint in perpetuity. It is made available under aCC-BY-NC-ND 4.0 International license.

623 sequence profiles were pooled in silico by plant to perform this power analysis at the individual

624 plant level.

625

626 Figure S1. The proportion of plant reads of the total bacterial/archaeal (a) and fungal (b) reads

627 showed that more than $90 \%$ reads obtained were plant contaminants.

628 
Bintarti et al.

(a) Bacteria/archaea
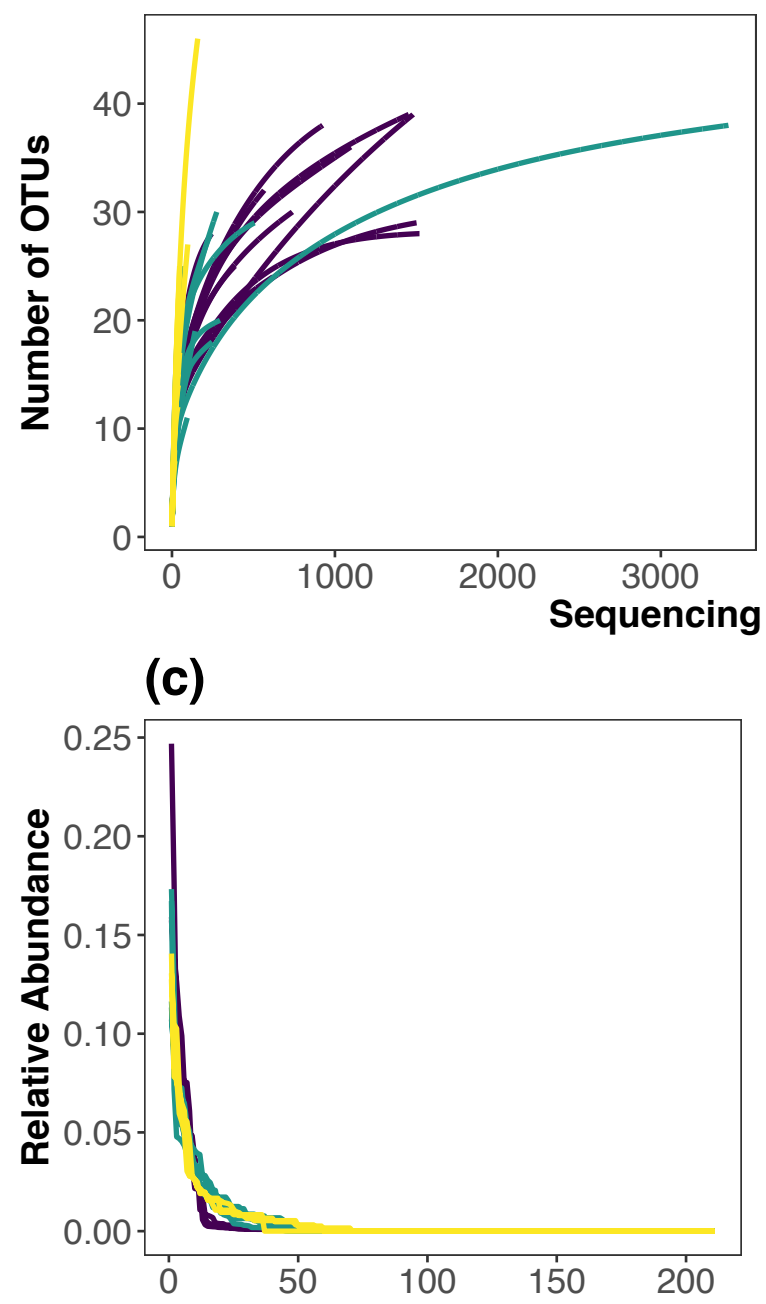

(b) Fungi

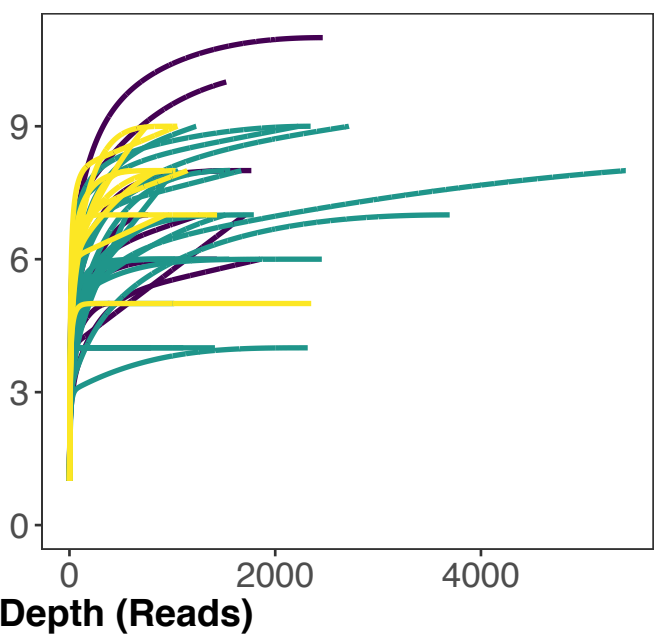

(d)

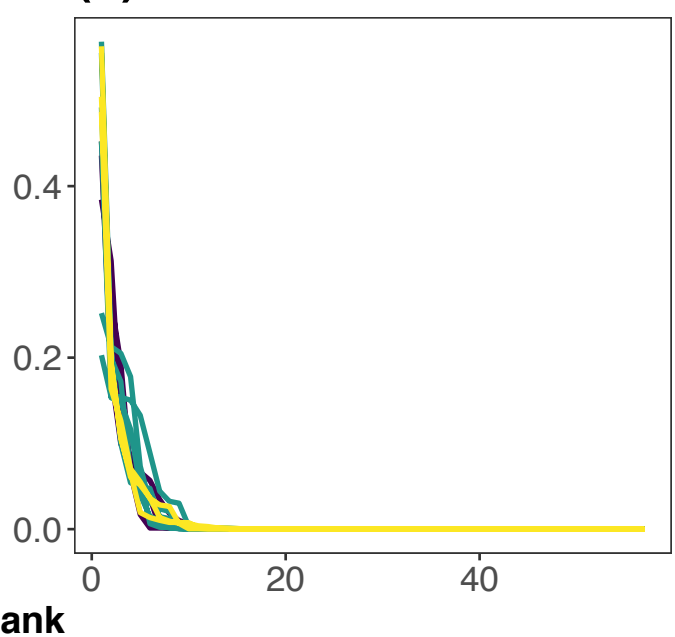

Plant

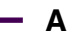

Fig 1. Rarefaction curves of bacteria/archaea (a) and fungi (b) from seed samples (marked) at 97 $\%$ of clustering threshold were constructed by plotting the OTU number after decontamination (microbial contaminants removal) to the sequence (read) number. The rarefaction curves were constructed using vegan package (v2.5-4). Rank abundance curve of decontaminated and normalized bacterial/archaeal (c) and fungal (d) OTU tables. Samples ( $n=47$ and $n=45$ for bacteria/archaea and fungi, respectively) were grouped by plant. 
Bintarti et al.

(a)

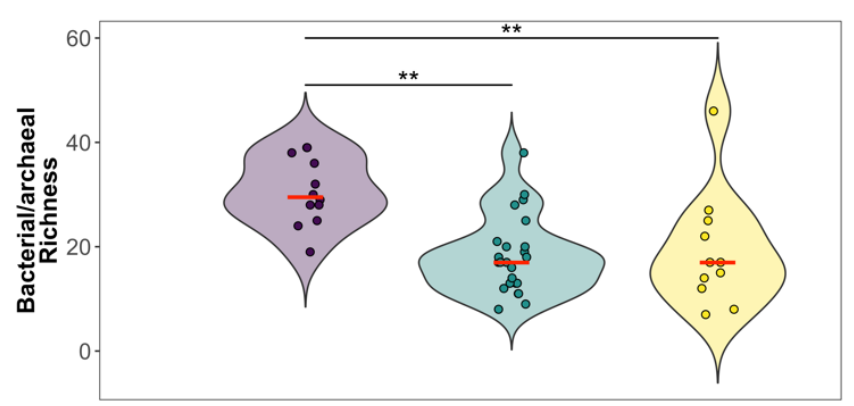

(c)

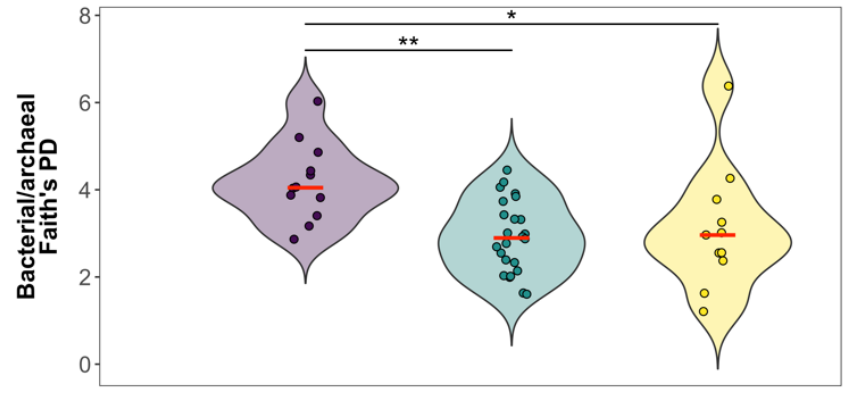

(e)

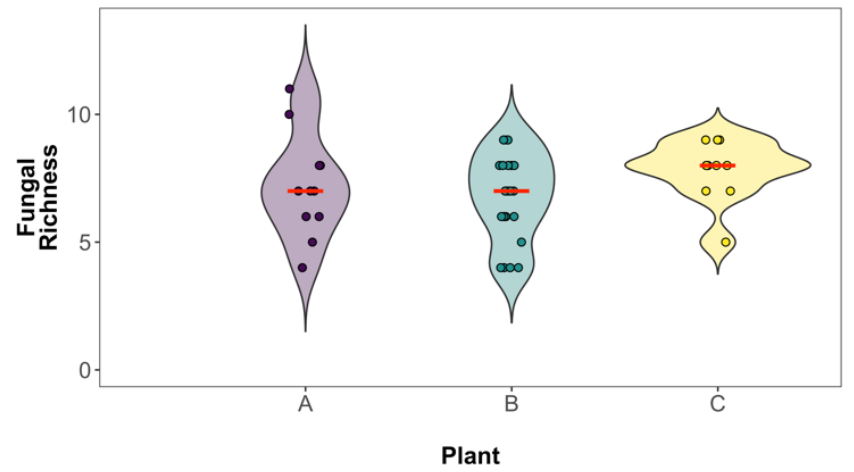

(b)

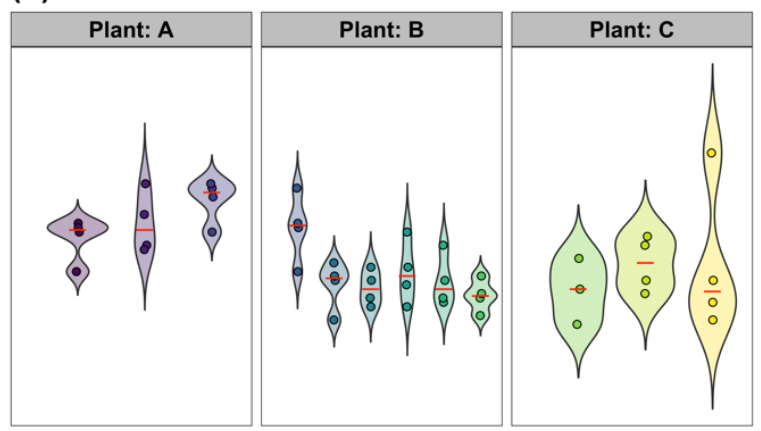

(d)

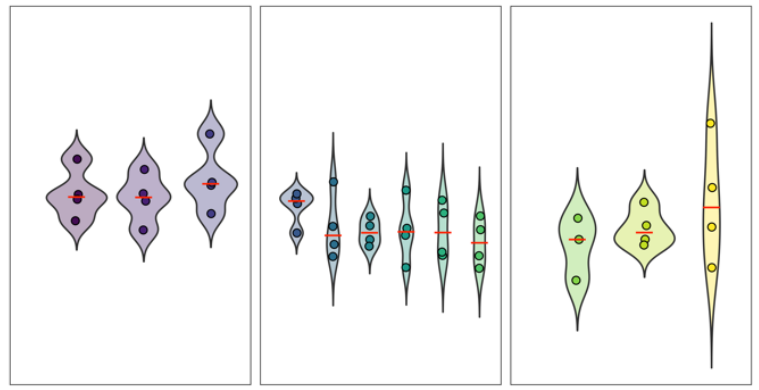

(f)

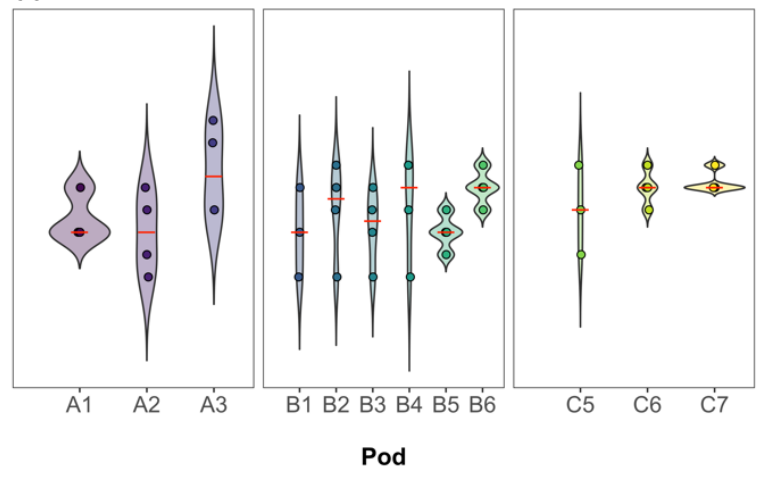

Fig 2. Bacterial/archaeal richness among plants were different (linear mixed-effects model, $\mathrm{LMM}$; df $=2$, F-value $=6.91, \mathrm{p}$-value $=0.015)(\mathrm{a})$, but not among pods within plant $(\mathrm{p}$-value $>$ $0.05)$ (b). Specifically, plant B and C displayed lower bacterial/archaeal richness compared to the plant A (Tukey's HSD post hoc test; $p$-value $=0.001$ and 0.006 , respectively).

Bacterial/archaeal phylogenetic diversity among plants were different (linear mixed-effects model, LMM; $d f=2$, F-value $=6.56, p$-value $=0.003)(c)$, but not among pods within plant $(p-$ value $>0.05)(d)$. Specifically, plant $B$ and $C$ displayed lower bacterial/archaeal phylogenetic diversity compared to the plant A (Tukey's HSD post hoc test, $p$-value $=0.001$ and 0.013 , respectively). Fungal richness was not different among plants (linear mixed-effects model, $\operatorname{LMM} ; \mathrm{df}=2, \mathrm{~F}$-value $=1.11, \mathrm{p}$-value $=0.37)(\mathrm{e})$ and among pods within plant $(\mathrm{p}$-value $=0.55)(f)$. 
Bintarti et al.

(a) Bacteria/archaea

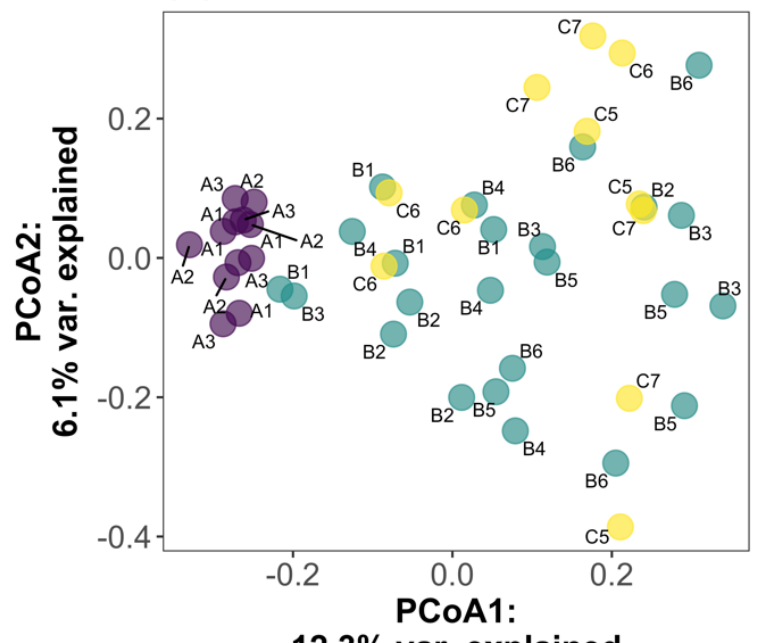

$12.3 \%$ var. explained

(c)

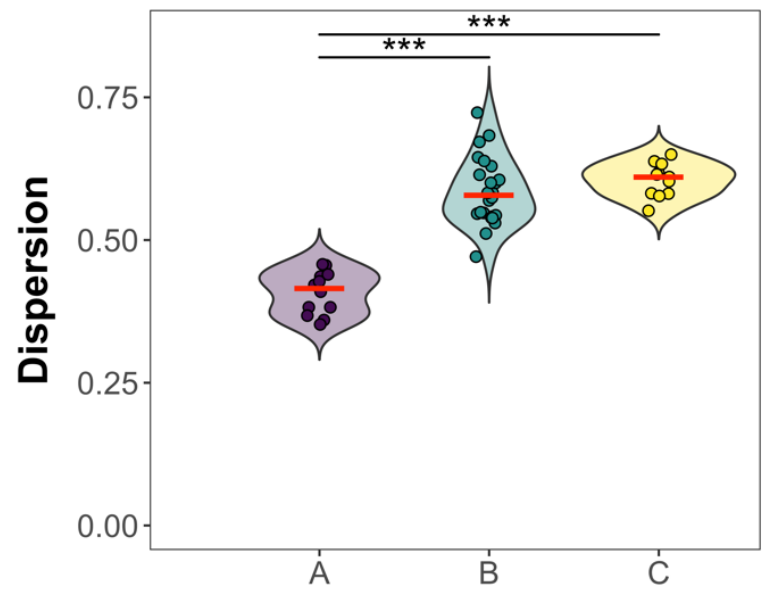

(b) Fungi

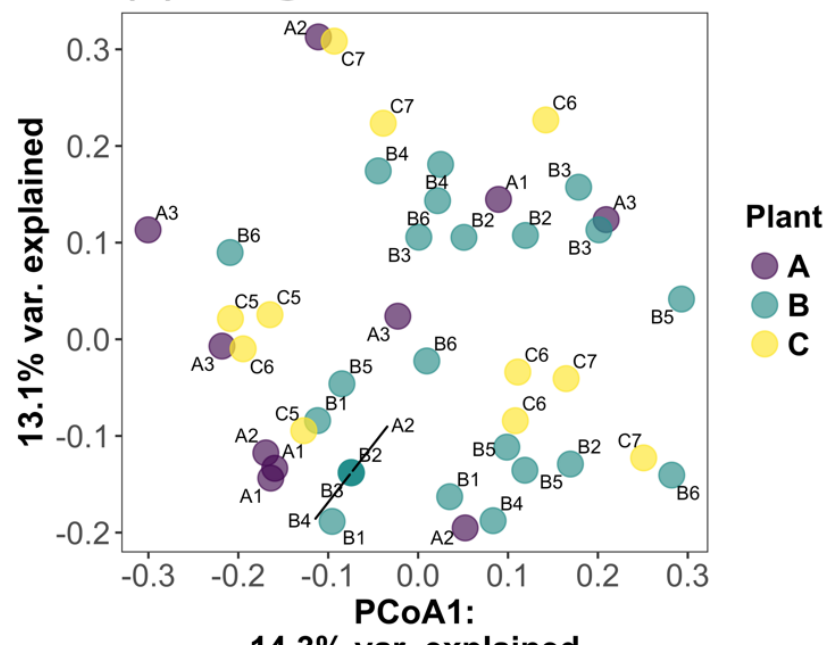

$14.3 \%$ var. explained

(d)

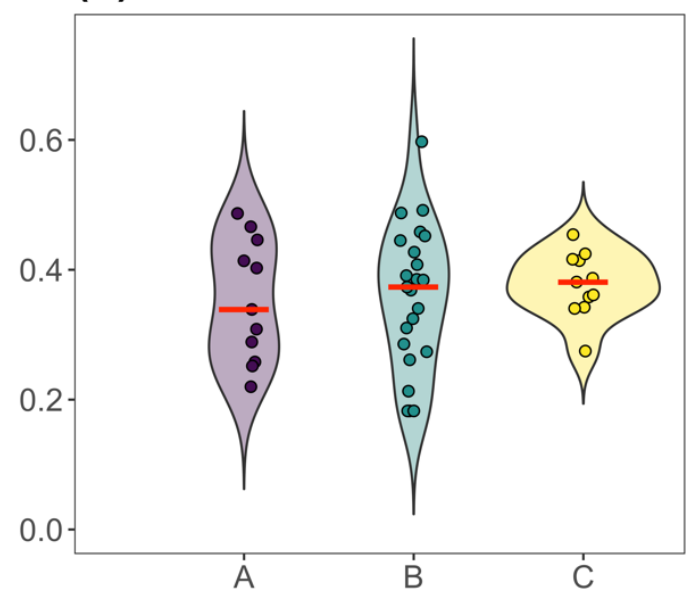

\section{Plant}

Fig 3. Principal coordinate analysis (PCoA) plot based on Jaccard dissimilarities of bacterial/archaeal (a) and fungal (b) OTUs. The samples were plotted and grouped based on plant as illustrated different colors. Each point was labelled by pod. Statistical analysis showed that seed bacterial/archaeal community structure differ among plants (nested PERMANOVA, df $=2$, F-ratio $=2.94$, $p$-value $=0.002$ ) but not pods (nested PERMANOVA, df =9, F-ratio $=0.99, p$ value $=0.63)$. Statistical analysis also showed that seed fungal community structure differs among plants (nested PERMANOVA, df $=2, F$-rati $=1.55, p$-value $=0.023$ ) and pods (nested PERMANOVA, df $=9, \mathrm{~F}$-ratio $=1.27, \mathrm{p}$-value $=0.03$ ). Distance to centroid analysis using betadisper function from the vegan package revealed that there is variation in bacterial/archaeal Beta diversity among plant (PERMADISP, df $=2$, F-value $=63.9, p$-value $=$ 9.6e-14) (c). In contrast, there were no variation in fungal Beta diversity among plant $($ PERMADISP, $\mathrm{df}=2$, F-value $=0.22, \mathrm{p}$-value $=0.802)(\mathrm{d})$. 
Bintarti et al.

\section{(a) Bacteria/archaea}

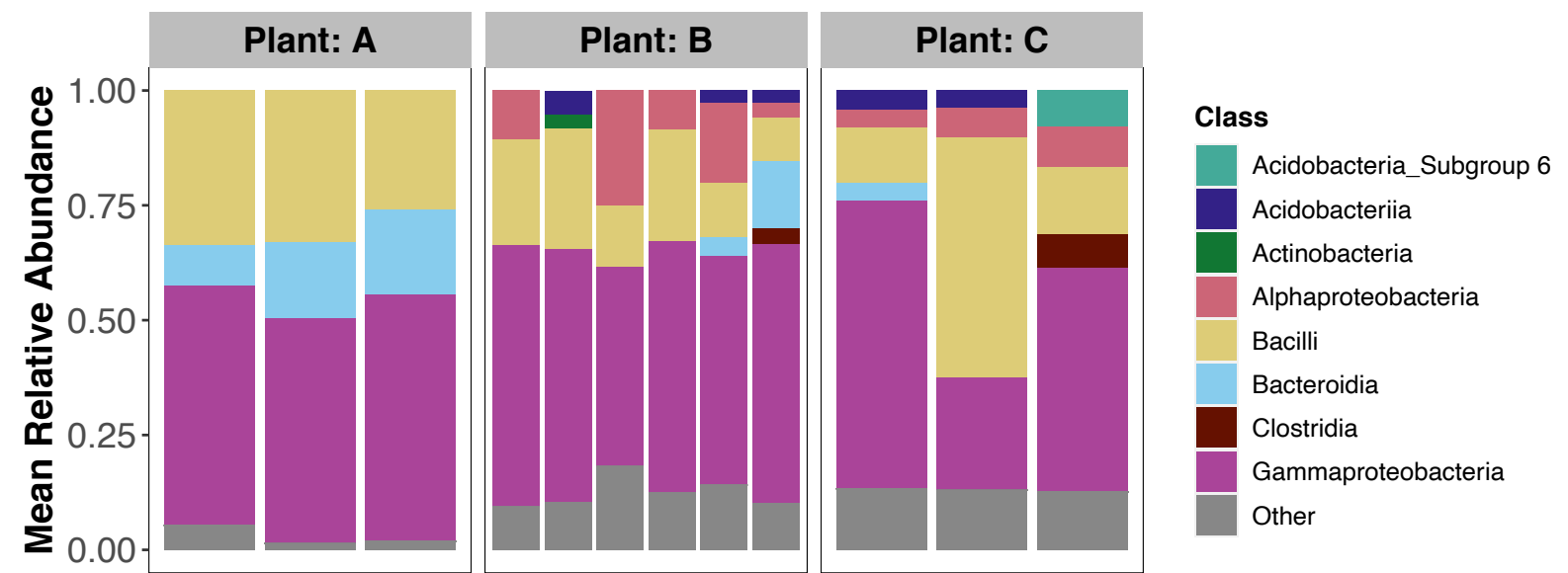

\section{(b) Fungi}
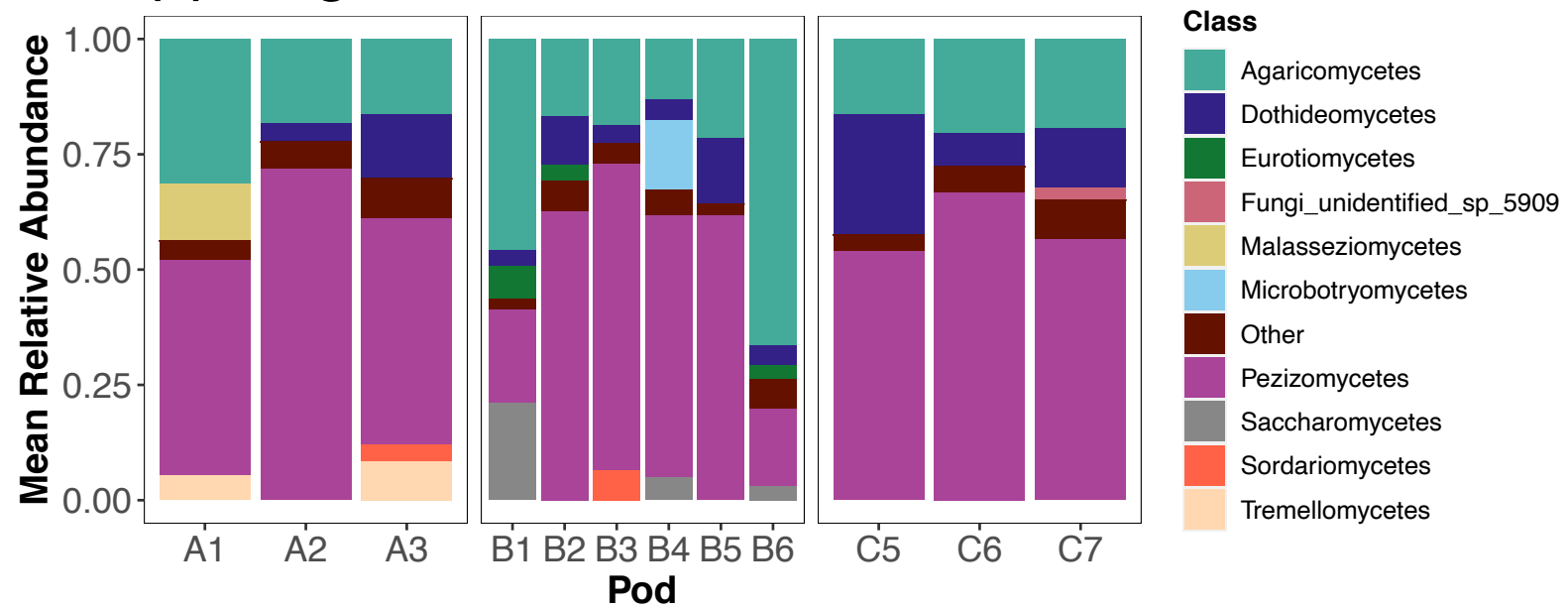

Fig 4. Bar plot represents mean relative abundances of bacterial/archaeal (a) and fungal (b) classes detected across plants. For bacteria/archaea, each pod consisted of 4 seeds (except for C5; 3 seeds); and for fungi, each pod consisted of 4 seeds (except for A1, B1 and C5; 3 seeds). The endophyte microbiome was assessed from the DNA extracted from single seed collected from each pod. Bacterial/archaeal and fungal classes with mean relative abundances of less than $10 \%$ were grouped into the 'Other' classification, which includes many lineages (not monophyletic). 
Bintarti et al.

(a)

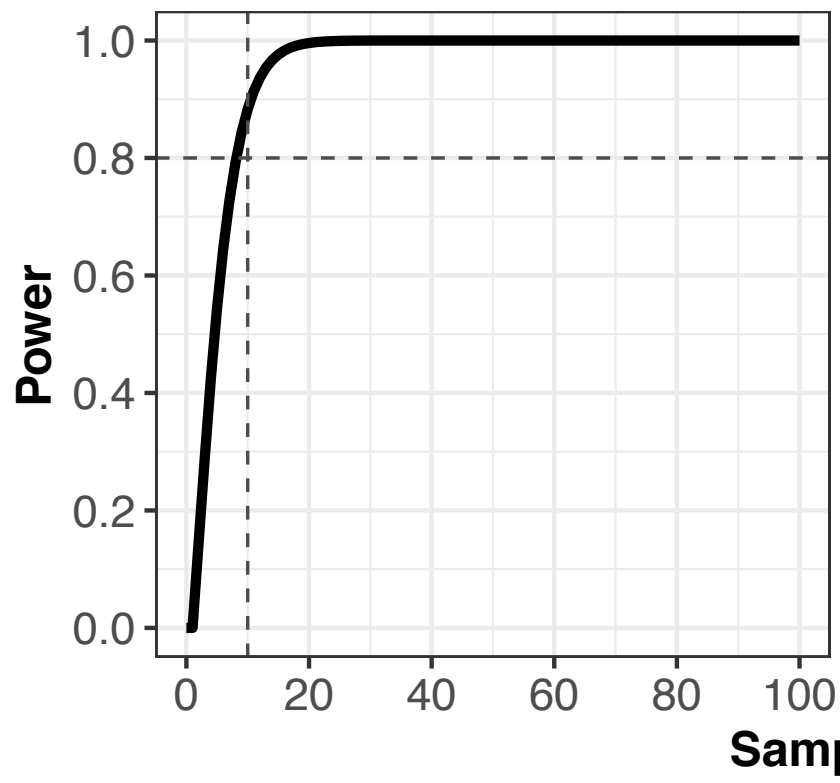

(b)

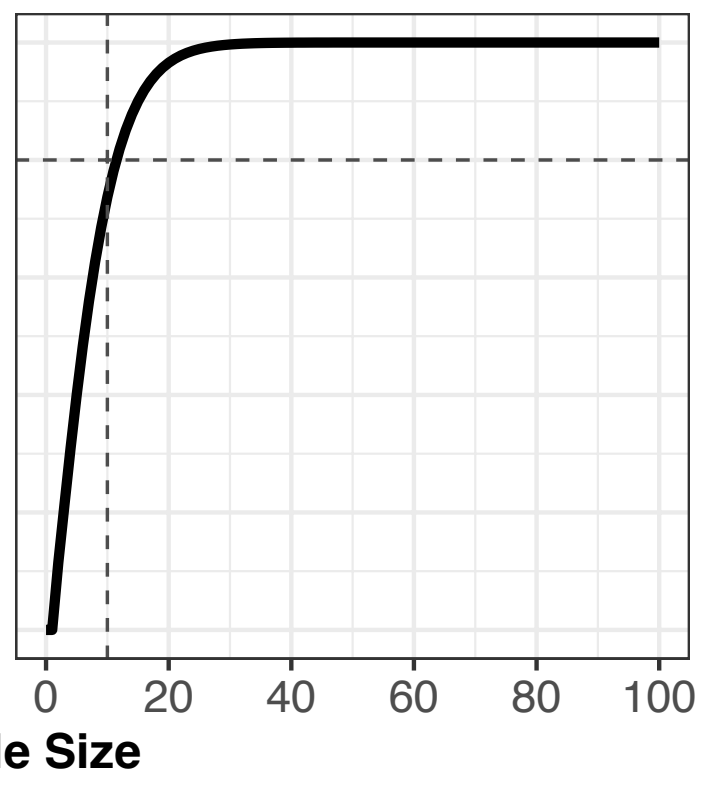

Fig 5. Analysis of power using pwr.t.test () function from the pwr package revealed that an effect of treatment on the 16S rRNA bacterial/archaeal alpha diversity (richness (a) and phylogenetic diversity (b)) would be detectable 12 plants at a power of 0.8 . Because the highest seed microbiome variability was at the maternal plant level, individual seed microbiome sequence profiles were pooled in silico by plant to perform this power analysis at the individual plant level. 